\title{
Determinants of VIA Positivity Among Women Screened for Cervical Precancerous Lesion in Public Hospitals of Oromia Region, Ethiopia: Unmatched Case-Control Study
}

This article was published in the following Dove Press journal:

International Journal of Women's Health

\author{
Yohannes Tekalegn (D) \\ Rameto Aman (iD) \\ Demelash Woldeyohannes (D) \\ Biniyam Sahiledengle (iD) \\ Sisay Degno $\mathbb{D}^{2}$ \\ 'School of Health Science, Department \\ of Public Health, Madda Walabu \\ University, Goba Referral Hospital, Goba, \\ Ethiopia; ${ }^{2}$ School of Medicine, \\ Department of Anatomy, Madda Walabu \\ University, Goba Referral Hospital, Goba, \\ Ethiopia
}

Purpose: Globally, cervical cancer is the fourth most frequent cancer among women. An estimated 570,000 cases of cervical cancer representing $6.6 \%$ of all female cancers were reported in the year 2018. Approximately, 90\% of deaths from cervical cancer occurred in low- and middle-income countries. Screening cervical cancer at an early stage and providing access to effective treatment can significantly improve the likelihood of survival. Hence, this study aimed to assess the determinants of visual inspection of cervix with acetic acid (VIA) positivity among women screened in public hospitals of Oromia region, Ethiopia.

Methods: A hospital-based un-matched case-control study was conducted in Oromia region, Ethiopia. Cases were women who have a positive result for the VIA test, and controls were women with a negative result. An interviewer-administered questionnaire was used to collect the data. Multiple binary logistic regressions were conducted to assess the determinants of VIA positivity. Adjusted odds ratios (AOR) with 95\% confidence intervals (CI) were reported to describe the strength of associations. Statistical significance was declared at a p-value $<0.05$.

Results: A total of 74 cases and 148 controls were included in this study. The mean age of cases and controls was $40.5 \pm 13.3$ years and $37.1 \pm 11.9$ years, respectively. Women with parity of four or more children had two times higher odds being positive for VIA test compared to their counterparts (AOR: 2.1,95\% CI: 1.3-4.0). Women with a history of post-coital bleeding had three times higher odds of VIA positivity compared to their counterparts (AOR: 3.3, 95\% CI: 1.2-8.0). History of sexually transmitted infection (AOR: $1.9,95 \% \mathrm{CI}$ : 1.1-3.5), having multiple sexual partners (AOR: 3.2, 95\% CI: 1.2-8.0), and history of smoking (AOR: 8.9, 95\% CI: 1.6-48.0) were also found to be determinants of VIA positivity.

Conclusion: This study found that women with parity greater than four children, post-coital bleeding, history of sexually transmitted infections, having multiple sexual partners, and history of smoking were significantly associated with VIA positivity. Women with the mentioned characteristics should be encouraged to have a close follow-up for the screening. Additionally, awareness creation activities on the identified risk factors are strongly recommended for all women.

Keywords: visual inspection of cervix with acetic acid, VIA positivity, cervical precancerous lesions, cervical cancer, determinants, factors associated, Oromia region, Ethiopia

\section{Introduction}

Cervical cancer is cancer that forms in the tissues of a cervix. It is usually slowgrowing cancer that may not have symptoms but can be found with regular Pap tests. ${ }^{1}$ Precancerous lesions are biologically defined as lesions that can progress
Correspondence: Yohannes Tekalegn Email yohannesefa@gmail.com 
potentially to invasive cervical cancer if left untreated. ${ }^{2-4}$ Human Papilloma Virus (HPV) is a necessary cause of cervical cancer, but it is not a sufficient cause, and other cofactors are required for progression from cervical HPV infection to cancer. ${ }^{5}$

Globally, cervical cancer is the fourth most frequent cancer among women. An estimated 570,000 cases representing $6.6 \%$ of all female cancers were reported in the year 2018. ${ }^{6}$ Approximately, 90\% of deaths from cervical cancer occurred in low- and middle-income countries. $^{7-10}$

In Ethiopia, cervical cancer ranks as the second leading cause of female cancer. About 7095 new cases are diagnosed annually and about 4732 deaths occur from the same cause in the same year. ${ }^{7}$ About $80 \%$ of reported cases of cancer in Ethiopia are diagnosed at advanced stages when very little can be done to treat the disease. This is largely due to the low awareness of cancer signs and symptoms, inadequate screening, early detection and treatment services, inadequate diagnostic facilities, and poorly structured referral system. ${ }^{11-13}$

Diagnosing cervical cancer at an early stage and providing access to effective treatment can significantly improve the likelihood of survival. ${ }^{14}$ However, the accessibility of the screening service, as well as the coverage of the Human Papillomavirus vaccine in most parts of the world, is not optimal. ${ }^{15-17}$

The standard practice is to screen women using cytology (Pap-test) but this screening method requires highly trained human resources and substantial amount of laboratory equipment. Because of the high cost of setting up these screening programs in low- and middle-income countries, alternative screening methods are needed. 5,14,18 Among available alternative techniques, visual inspection with acetic acid (VIA) involves an examination of the cervix with the naked eye, using a bright light source, after $1 \mathrm{~min}$ of 3-5\% dilute acetic acid application using a cotton swab or a spray. Detection of well-defined acetowhite areas close to the squamocolumnar junction (SCJ) indicates a positive test. ${ }^{18,19}$ The test characteristics of VIA have been evaluated in several cross-sectional studies in less-developed countries. These studies have reported promising results that support its use as an alternative to cervical cytology. ${ }^{20-24}$

In Ethiopia, few studies have been conducted to assess the predictors of the cervical precancerous lesion. Factors identified by those studies were: being in the older age group, having multiple sexual partners, parity greater than four children, initiation of sexual intercourse at an early age, history of sexually transmitted infections, long-term use of oral contraceptives. ${ }^{25-29}$ The aim of this study was to assess the determinants of VIA positivity among women screened for cervical precancerous lesions in selected hospitals of the Oromia region, Ethiopia using a case-control study design.

\section{Materials and Methods}

Study Design, Population and Sample Size

A facility-based unmatched case-control study was conducted in hospitals screening women for cervical precancerous lesions using visual inspection of the cervix with acetic acid (VIA) in the Oromia region, Ethiopia. Based on the 2007 census conducted by the Central Statistical Agency of Ethiopia (CSA), Oromia Region has a total population of 26,993,933, consisting of 13,595,006 men and 13,398,927 women; urban inhabitants number $3,370,040$ or $11.3 \%$ of the population. With an estimated area of $353,006.81$ square kilometers, this region has an estimated population density of 76.93 people per square kilometer.

Three hospitals providing regular screening services for cervical precancerous lesions were selected for this study. The three selected hospitals were Robe general hospital, Shashemene referral hospital, and Bishoftu general hospital. All women screened for the precancerous lesion of the cervix in those selected hospitals were the source population for this study. The total sample size was allocated to each selected hospital using probability proportionate to the average monthly number of women screened and case detection rate, which was reviewed from registration books of respective hospitals. We used a case-based control selection method; whenever one case was selected two controls were included from a similar hospital until the required sample size fulfilled.

The sample size was calculated online using Open-Epi version 3.01, considering the parameters of a 95\% level of confidence, $80 \%$ power, taking 1:2 cases to controls ratio. Considering sexuality transmitted infections to be a significant determinant of the cervical precancerous lesion which was reviewed from different reviewed literature, $19.3 \%$ proportion of sexually transmitted disease among cases, and $6.1 \%$ proportion of sexually transmitted infection among control. ${ }^{26}$ After adding a $10 \%$ nonresponse rate, the final sample size was 77 cases and 153 controls. 


\section{Data Collection Tools and Instruments}

A structured data collection tool was developed after reviewing the literature and client record/logbook. ${ }^{26-28,30}$ The questionnaire was first prepared in English, and translated to local language (Afan-Oromo) and finally back-translated to English to ensure consistency. The questionnaire includes questions about the socio-demographic and economic characteristics, reproductive, lifestyle, and sexual behavior of the study participants ( $\underline{\text { 1 File) }}$. Data were collected through face to face interviews using a structured data collection questionnaire in a private room to maintain the privacy of study participants. Data collectors were recruited among health practitioners in the study hospitals with clinical experience and training on screening of cervical precancerous lesions. Data collectors were provided with training on the objective of the study, contents of the questionnaires, and how to maintain confidentiality and privacy of the study participants. All questionnaires were checked for completeness every day by the principal investigator and supervisors.

\section{Data Analysis Method}

Data were entered into EpiData version 3.1 then exported to Statistical Package for Social Science (SPSS) version 20. Data were cleaned by running simple frequency distributions, summary statistics, and cross-tabulation. Descriptive statistics were used to summarize the sociodemographic and clinical characteristics of the study participants. Odds ratios with $95 \%$ confidence intervals (CI) were computed to identify the presence and strength of association. Variables with p-value $<0.05$ in the univariate binary logistic regression analysis were included in a multiple binary logistic regression analysis to assess the individual effect of each variable on the outcome variable. Multicollinearity between independent variables was assessed using the variance inflation factor (VIF) before entering the variables into the final model. The final model of multiple binary logistic regressions was fitted using a forward method with Hosmer and Lemeshow goodness of fit test $(\mathrm{p}=0.27)$. Statistical significance was declared at $\mathrm{p}$-value $<0.05$.

\section{Ethical Consideration}

This study conducted following the principles of the declarations of Helsinki. Ethical clearance was obtained from the ethical review committee of MaddaWalabuUniversity. After receiving ethical clearance, permission to conduct the research was obtained from respective hospitals. An information sheet was prepared and read to all eligible participants of the study to obtain written informed consent, all participants were informed about the purpose of the study and their participation was voluntary. Women with positive results of VIA were treated immediately following the screening whereas suspicious invasive cervical cancer findings were linked to gynecology clinic for further diagnosis.

\section{Operational Definitions}

\section{Precancerous Lesion of the Cervix}

A premalignant lesion of the uterine cervix that can progress to cervical cancer if left untreated.

Visual Inspection of the Cervix with Acetic Acid (VIA) Screening method which involves naked-eye inspection of the uterine cervix 1 min after application of a 3-5\% solution of acetic acid using a cotton swab or a spray.

\section{Cases}

The appearance of aceto-white areas in the transformation zone, close to the squamocolumnar junction, or the os by VIA test.

\section{Controls}

The absence of aceto-white areas in the transformation zone, close to the squamocolumnar junction or the os by VIA test.

\section{Sexually Transmitted Infections (STI)}

In this study, STI refers to women with a history of STI related syndromes such as lower abdominal pain, vaginal discharge, pain in urination, genital ulcer, and/or inguinal bubo.

\section{Results}

A total of 74 cases and 148 controls were included in this study with a response rate of $96.1 \%$. The age of women in this study ranges from 21 to 50 years old. The mean age of cases and controls with their standard deviations were 40.5 \pm 13.3 years and $37.1 \pm 11.9$ years, respectively. Fortyseven $(63.5 \%)$ of cases and $116(78.4 \%)$ of controls were married (Table 1).

\section{Reproductive Health-Related Characteristics of Study Participants}

As described in Table 2, the history of contraceptive use in this study was 47 (53.5\%) among cases and 114 (77\%) among controls. The most frequent type contraceptive method used was Injectable (Depo-Provera), 36 (48.6\%), 
Table I Sociodemographic Characteristics of Women Screened for a Precancerous Lesion of the Cervix in Oromia Region, Ethiopia, 2019

\begin{tabular}{|c|c|c|c|c|}
\hline Variables & Cases, n (\%) & Controls, n (\%) & COR $(95 \% \mathrm{Cl})$ & p-value \\
\hline \multicolumn{5}{|l|}{ Age (years) } \\
\hline $21-30$ & $9(12.2)$ & $38(25.7)$ & I & \\
\hline $31-40$ & $45(60.8)$ & $87(58.8)$ & $2.2(0.9-4.9)$ & 0.06 \\
\hline $4 I-50$ & $20(27)$ & $23(15.5)$ & $3.7(1.4-9.4)$ & $0.007^{*}$ \\
\hline \multicolumn{5}{|l|}{ Educational status } \\
\hline No formal education & $28(37.8)$ & $48(32.4)$ & 1 & \\
\hline Primary education & $22(29.7)$ & $54(36.5)$ & $0.7(0.3-1.4)$ & 0.3 \\
\hline Secondary education & $18(24.3)$ & $35(23.6)$ & $0.9(0.4-1.8)$ & 0.7 \\
\hline College and above & $6(8.1)$ & II (7.4) & $0.9(0.3-2.8)$ & 0.9 \\
\hline \multicolumn{5}{|l|}{ Marital status } \\
\hline Single & I (I.4) & $9(6.1)$ & I & \\
\hline Married & $47(63.5)$ & $116(78.4)$ & $3.6(0.5-29.6)$ & 0.2 \\
\hline Widowed & $12(16.2)$ & $6(4.1)$ & $18(1.8-177)$ & $0.01 *$ \\
\hline Divorced & $14(19.0)$ & I7 (II.5) & $7.4(0.8-65)$ & 0.07 \\
\hline \multicolumn{5}{|l|}{ Occupation } \\
\hline Housewife & $35(47.3)$ & $80(54)$ & I & \\
\hline Merchant & $16(21.6)$ & $22(14.9)$ & $1.6(0.8-3.5)$ & 0.2 \\
\hline Daily labourer & $14(18.9)$ & $17(11.5)$ & $1.8(0.8-4.2)$ & 0.1 \\
\hline Government employee & $7(9.5)$ & $15(10.1)$ & I.I (0.4-2.8) & 0.9 \\
\hline Others & $2(2.7)$ & $14(9.5)$ & $0.3(0.1-1.5)$ & 0.1 \\
\hline \multicolumn{5}{|l|}{ Religion } \\
\hline Muslim & $20(27.0)$ & $48(32.4)$ & I & \\
\hline Orthodox Christian & $37(50.0)$ & $72(48.6)$ & $1.2(0.6-2.3)$ & 0.5 \\
\hline Protestant or catholic & $17(23.0)$ & $28(19.0)$ & $1.4(0.6-3.2)$ & 0.4 \\
\hline \multicolumn{5}{|c|}{ Family income per month in Ethiopian birr } \\
\hline$<1500$ & $30(40.5)$ & $73(32.9)$ & 1 & \\
\hline $1500-2999$ & $20(27.0)$ & $61(27.5)$ & $0.7(0.3-1.4)$ & 0.3 \\
\hline $3000-4999$ & $16(21.6)$ & $60(27.0)$ & $0.5(0.2-1.1)$ & 0.08 \\
\hline$\geq 5000$ & $8(10.8)$ & $20(13.5)$ & $0.5(0.2-1.4)$ & 0.2 \\
\hline
\end{tabular}

Note: *Significant at $\mathrm{p}<0.05$ (crude).

and $65(43.9 \%)$ among cases and controls, respectively. Nineteen $(25.7 \%)$, and $5(3.4 \%)$ of cases and controls had a history of post-coital bleeding, respectively. Seventy (94.6\%) of cases and 129 (87.2) of controls had ever given birth. Thirty-seven (50\%) of cases and $54(36.5 \%)$ of controls had at least one history of abortion in their lifetime. Among study participants, 16 (21.6\%) of cases, and $3(2.0 \%)$ of controls had a family history of cervical cancer.

\section{Lifestyle and Sexual Related}

\section{Characteristics of Study Participants}

Among study participants, $10(13.5 \%)$ of cases, and 4 $(2.7 \%)$ of controls had ever been screened for cervical cancer before the current screening. Fourteen (18.9\%) of cases and $4(2.7 \%)$ of controls had a history of smoking. Sixty $(81.1 \%)$ of cases and $114(77 \%)$ of controls had never used a condom in their lifetime. Regarding sexually transmitted infections (STI), 50 (67.6\%) of cases, and 48 (32.4\%) of controls had a history of STI. In terms of HIV status, $26(36.6 \%)$ of cases and 35 (24.1) of controls were HIV positives (Table 3).

\section{Factors Associated with VIA positivity}

In the univariate binary logistic regression; age, marital status, use of contraceptive, age at first birth, parity, post-coital bleeding, family history of cervical cancer, being ever screened for cervical cancer, history of smoking, pelvic inflammatory disease, sexually transmitted infection, 
Table 2 Reproductive Health-Related Characteristics of Women Screened for a Precancerous Lesion of the Cervix in Oromia Region, Ethiopia, 2019

\begin{tabular}{|c|c|c|c|c|}
\hline Variables & Cases, n (\%) & Control, n (\%) & COR & P-value \\
\hline \multicolumn{5}{|c|}{ Ever use of contraceptive } \\
\hline Yes & $47(63.5)$ & II 4 (77) & $0.5(0.3-0.9)$ & $0.04 *$ \\
\hline No & $27(36.5)$ & $34(23)$ & 1 & \\
\hline \multicolumn{5}{|c|}{ Oral contraceptive use } \\
\hline Yes & I (I.4) & $7(4.7)$ & $0.3(0.03-2.3)$ & 0.2 \\
\hline No & $73(98.6)$ & $|4|(95.3)$ & I & \\
\hline \multicolumn{5}{|c|}{ Duration of oral contraceptive use } \\
\hline$<5$ years & $0(0)$ & $5(3.4)$ & 1 & \\
\hline$\geq 5$ years & I (I.4) & $2(1.3)$ & $0.7(0.3-5.5)$ & 0.8 \\
\hline \multicolumn{5}{|c|}{ Injectable (Depo-Provera) use } \\
\hline Yes & $36(48.6)$ & $65(43.9)$ & $1.2(0.7-2.1)$ & 0.5 \\
\hline No & $38(51.3)$ & $83(56.1)$ & 1 & \\
\hline \multicolumn{5}{|c|}{ Duration of Injectable (Depo-Provera) use } \\
\hline$<5$ years & $19(25.7)$ & $38(25.7)$ & 1 & \\
\hline$\geq 5$ years & $17(23)$ & $27(18.2)$ & $0.8(0.3-6.4)$ & 0.9 \\
\hline \multicolumn{5}{|l|}{ Implant use } \\
\hline Yes & $5(6.8)$ & $22(14.9)$ & $0.4(0.1-1.1)$ & 0.08 \\
\hline No & $69(93.2)$ & $126(85.1)$ & 1 & \\
\hline \multicolumn{5}{|c|}{ Duration of implant use } \\
\hline$<5$ years & $4(5.4)$ & $12(8.1)$ & I & \\
\hline$\geq 5$ years & $\mathrm{I}(\mathrm{l} .4)$ & $10(6.8)$ & $0.3(0.03-3.1)$ & 0.3 \\
\hline \multicolumn{5}{|c|}{ Intrauterine contraceptive device use } \\
\hline Yes & $5(6.8)$ & $20(13.5)$ & $0.4(0.2-1.2)$ & 0.2 \\
\hline No & $69(93.2)$ & $128(86.5)$ & 1 & \\
\hline \multicolumn{5}{|c|}{ Duration of intrauterine contraceptive device use } \\
\hline$<5$ years & $2(2.8)$ & $8(5.4)$ & I & \\
\hline$\geq 5$ years & $3(4)$ & $12(8.1)$ & $0.9(0.1-7.3)$ & 0.9 \\
\hline \multicolumn{5}{|l|}{ Age at menarche } \\
\hline$\leq 12$ years & $4(5.4)$ & $4(2.7)$ & 1 & \\
\hline $13-14$ years & $50(67.6)$ & $80(54.1)$ & $0.6(0.1-2.6)$ & 0.5 \\
\hline$\geq 15$ years & $20(27)$ & $64(43.2)$ & $0.3(0.07-1.3)$ & 0.1 \\
\hline \multicolumn{5}{|l|}{ Menstrual history } \\
\hline Regular & $27(36.5)$ & $71(48)$ & 1 & \\
\hline Sometimes irregular & $30(40.5)$ & $42(28.4)$ & $1.8(0.9-3.5)$ & 0.06 \\
\hline Always irregular & $12(16.2)$ & $26(17.6)$ & $1.2(0.5-2.7)$ & 0.6 \\
\hline No menses & $5(6.8)$ & $9(6.1)$ & $1.4(0.4-4.7)$ & 0.5 \\
\hline \multicolumn{5}{|l|}{ Post coital bleeding } \\
\hline Yes & $19(25.7)$ & $5(3.4)$ & $9.8(3.5-27)$ & $<0.001 *$ \\
\hline No & $55(74.3)$ & $143(96.6)$ & 1 & \\
\hline \multicolumn{5}{|l|}{ Ever gave birth } \\
\hline Yes & $70(94.6)$ & $129(87.2)$ & $2.5(0.8-7.8)$ & 0.09 \\
\hline No & $4(5.4)$ & $19(12.8)$ & 1 & \\
\hline
\end{tabular}


Table 2 (Continued).

\begin{tabular}{|c|c|c|c|c|}
\hline Variables & Cases, n (\%) & Control, n (\%) & COR & P-value \\
\hline \multicolumn{5}{|l|}{ Parity } \\
\hline $1-3$ & $31(44.3)$ & $76(58.9)$ & 1 & \\
\hline$\geq 4$ & $39(55.7)$ & $53(4 I .1)$ & $1.8(\mathrm{I} .0 \mathrm{I}-3.2)$ & $0.04 *$ \\
\hline \multicolumn{5}{|c|}{ Age at first birth } \\
\hline$\leq 18$ years & $37(52.9)$ & $45(34.6)$ & I & \\
\hline $19-30$ years & $31(44.3)$ & $77(59.2)$ & $0.5(0.3-0.9)$ & $0.02 *$ \\
\hline$>30$ years & $2(2.9)$ & $8(6.2)$ & $0.3(0.1-1.7)$ & 0.2 \\
\hline \multicolumn{5}{|c|}{ Average birth interval } \\
\hline$<2$ years & $10(14.3)$ & $13(10)$ & I & \\
\hline $2-3$ years & $4 \mid(58.6)$ & $81(62.3)$ & $0.6(0.3-1.9)$ & 0.3 \\
\hline$>3$ years & $19(27.1)$ & $36(27.7)$ & $0.7(0.2-1.9)$ & 0.4 \\
\hline \multicolumn{5}{|c|}{ History of abortion } \\
\hline Yes & $37(50)$ & $54(36.5)$ & $1.7(0.9-3.06)$ & 0.06 \\
\hline No & $37(50)$ & $94(63.5)$ & 1 & \\
\hline \multicolumn{5}{|c|}{ Number of time faced abortion } \\
\hline I-2 times & $31(83.8)$ & $52(94.5)$ & 1 & \\
\hline$\geq 3$ times & $6(16.2)$ & $3(5.5)$ & $3.3(0.8-14.3)$ & 0.1 \\
\hline \multicolumn{5}{|c|}{ Family history of cervical cancer } \\
\hline Yes & $16(21.6)$ & $3(2.0)$ & $130.3(3.7-47.4)$ & $<0.00 I^{*}$ \\
\hline No & $58(78.4)$ & $145(98.0)$ & 1 & \\
\hline
\end{tabular}

Note: *Significant at $\mathrm{p}$-value $<0.05$ (crude).

partners' history of sexually transmitted infection (STI), genital ulcer or swelling, HIV status, and lifetime number of sexual partners were associated with VIA positivity.

After controlling for the effect confounders in multiple binary logistic regressions: parity, post-coital bleeding, smoking, and history of STI and lifetime number of sexual partners of women were found to be determinant factors for the VIA positivity. Women with parity of four or more had two times higher $(\mathrm{AOR}=2.1,95 \% \mathrm{CI}: 1.3-4.0)$ risk of being positive for the VIA test compared to those with parity of less than four. Women with a history of post-coital bleeding were more likely (AOR: 3.3, 95\% CI: 1.2-8.0) to be positive for the VIA test compared to those who did not have a history of post-coital bleeding. Women with a history of smoking had higher odds of being positive for the VIA test (AOR: 8.9, 95\% CI: 1.6-48) compared to non-smokers. Women with a history of STI were associated with higher odds of being positive for the VIA test (AOR: $1.9,95 \%$ CI: 1.1-3.5) compared to those without a history of STI. Women with three or more sexual partners in their lifetime were significantly associated with VIA positivity (AOR: $3.2,95 \% \mathrm{CI}$ : 1.2-8) compared to their counterparts (Table 4).

\section{Discussion}

This study aimed to assess the determinants of visual inspection of uterine cervix with acetic acid (VIA) positivity among screened women in selected hospitals of Oromia region, Ethiopia. In this study, parity, post-coital bleeding, smoking, and history of sexually transmitted infection (STI), and lifetime number of sexual partners of women were found to be significant determinants of VIA positivity.

In the present study, $67.6 \%$ of cases and $32.4 \%$ of control had a history of STI as reported by women depending on the common STI related syndromes described under the operational definitions section. This finding indicates that women with a history of STI have a higher chance of being infected by the human papillomavirus, a sexually transmitted infection, and the most important risk factor of cervical cancer. ${ }^{5}$ The magnitude of human immunodeficiency virus (HIV) infection among cases and controls was $36.6 \%$, and $24.1 \%$, respectively. This represents that women with HIV infection might have exposed to other sexually transmitted diseases where the human Papillomavirus is not an exception. 
Table 3 Lifestyle- and Sexual-Related Characteristics of Women Screened for a Precancerous Lesion of the Cervix in Oromia Region, Ethiopia, 2019

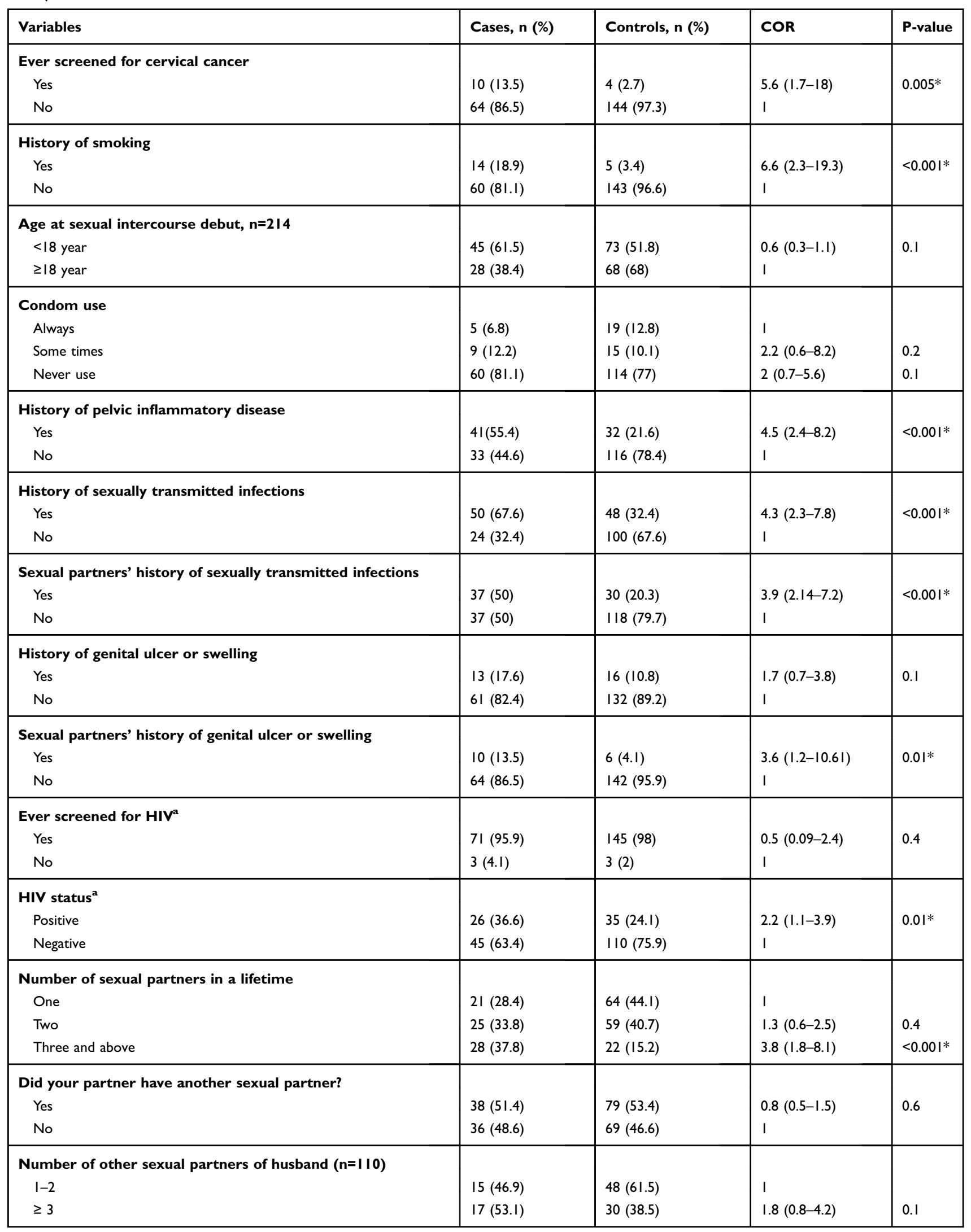

Notes: *Significant at $\mathrm{p}$-value $<0.05$ (crude); ${ }^{\mathrm{a}}$ Human immunodeficiency virus. 
Table 4 Multiple Binary Logistic Regression Analysis of Factors Associated with via Positivity Among Screened Women, Oromia Region, Ethiopia, 2019

\begin{tabular}{|c|c|c|c|c|}
\hline Variables & Cases, $\mathbf{n}(\%)$ & Control, n (\%) & AOR $(95 \% \mathrm{Cl})$ & P-value \\
\hline \multicolumn{5}{|l|}{ Parity } \\
\hline $1-3$ & $31(44.3)$ & $76(58.9)$ & I & \\
\hline$\geq 4$ & $39(55.7)$ & $53(4 I .1)$ & $2.3(1.3-4.0)$ & $0.004 * *$ \\
\hline \multicolumn{5}{|c|}{ Post coital bleeding } \\
\hline Yes & $19(25.7)$ & $5(3.4)$ & $3.3(1.2-8.0)$ & $0.01 * *$ \\
\hline No & $55(74.3)$ & $143(96.6)$ & 1 & \\
\hline \multicolumn{5}{|l|}{ History of smoking } \\
\hline Yes & $14(18.9)$ & $5(3.4)$ & $8.9(1.6-48.0)$ & $0.01 * *$ \\
\hline No & $60(81.1)$ & $143(96.6)$ & I & \\
\hline \multicolumn{5}{|c|}{ History of sexually transmitted infections } \\
\hline Yes & $50(67.6)$ & $48(32.4)$ & $1.9(1.1-3.5)$ & $0.006 * *$ \\
\hline No & $24(32.4)$ & $100(67.6)$ & 1 & \\
\hline \multicolumn{5}{|c|}{ Number of the sexual partner in a lifetime } \\
\hline One & $21(28.4)$ & $64(44.1)$ & I & \\
\hline Two & $25(33.8)$ & $59(40.7)$ & $1.2(0.6-2.3)$ & 0.6 \\
\hline Three and above & $28(37.8)$ & $22(15.2)$ & $3.2(1.2-8.3)$ & $0.01 * *$ \\
\hline \multicolumn{5}{|l|}{ Age group } \\
\hline $21-30$ & $9(12.2)$ & $38(25.7)$ & 1 & \\
\hline $31-40$ & $45(60.8)$ & $87(58.8)$ & $1.3(0.5-2.9)$ & 0.4 \\
\hline $4 \mid-50$ & $20(27)$ & $23(15.5)$ & $2.3(0.9-5.7)$ & 0.07 \\
\hline \multicolumn{5}{|l|}{ HIV status ${ }^{a}$} \\
\hline Positive & $26(36.6)$ & $35(24.1)$ & $0.8(0.4-1.9)$ & 0.7 \\
\hline Negative & $45(63.4)$ & 110 (75.9) & 1 & \\
\hline
\end{tabular}

Notes: **Significant at $\mathrm{p}$-value $<0.05$ (adjusted), ${ }^{\mathrm{a}}$ Human immunodeficiency virus. Abbreviation: AOR, adjusted odds ratio.

This study finding revealed that women with parity of four or more children had two times higher risk of being positive for the VIA test compared to those with parity of less than four. This finding is supported by a previous study conducted in Debremarkos and Jimma (Ethiopia), which showed parity of greater than four children were associated with a higher risk of cervical surface epithelial cell abnormalities. ${ }^{25,27}$ Also, the finding was in line with a review reported by Castellsague et $\mathrm{al}^{31}{ }^{31}$ and a population-based cohort study conducted by Jensen et al. ${ }^{32}$ However, this finding contradicts with previous studies conducted in Rwanda and Israel that reported high parity as a protective factor ( $\mathrm{AOR}=0.42$ and 0.39 , respectively) for cervical cancer. ${ }^{33,34}$

In the present study, women with a history of post-coital bleeding (PCB) had three times higher odds of being positive forVIA than their counterparts. This finding is supported by the previous study conducted in Israel, found that PCB as a significant risk factor for cervical dysplasia $(\mathrm{AOR}=1.82) .{ }^{34}$ Women who have a history of smoking had nine times higher odds of being positive for VIAthan non-smokers. In line with this finding the European Prospective Investigation into Cancer and Nutrition data reported smoking status, duration and intensity showed a two-fold increased risk of cervical intraepithelial neoplasia of grade 3 or carcinoma in situ, and invasive cervical cancer. ${ }^{35}$ Another similar prospective follow-up study found that long-term smoking more than 8 years was associated with increased risk of cervical intraepithelial neoplasia grade 3 or more. ${ }^{36}$

This study also found that women with a history of STI had two times higher odds of being positive for VIA compared to their counterparts. This association is supported by several previous studies conducted in Ethiopia and elsewhere. ${ }^{26,28,29,37,38}$ This could be related to the fact that women with a history of STI had a higher risk of being infected by the human Papillomavirus. Since human papillomavirus is the most known risk factor for cervical cancer. ${ }^{5}$

This study also found that women with multiple sexual partners were more likely to be positive for the VIA test. This 
finding is in line with several previous studies. ${ }^{26-29,37-39}$ This might be related to that women with multiple sexual partners have a higher risk of being infected by the human Papillomavirus.

The findings of this study should be used in light of the following limitations: The study included a relatively small sample size and there might be high-risk type 2 errors, the study discussed determinants of VIA positivity since cases and controls were identified by VIA. Histopathological confirmation for cervical precancerous lesion and HPV status of women was not addressed by this study. Hence, the study cannot say whether the identified risk factors are risk factors for HPV acquisition, HPV persistence, or progression to cervical intraepithelial neoplasia. Some of the questions regarding the sexual and reproductive history of the study participants are sensitive, social desirability bias might have affected the responses. Recall bias might also be the other possible limitation of the present study.

\section{Conclusions}

In this study parity greater than four children, post-coital bleeding, history of sexually transmitted infections, having multiple sexual partners, and history of smoking were found to be determinant factors for the VIA positivity. Women with the mentioned characteristics should be encouraged to have a close follow-up for the screening. Additionally, awareness creation activities on the identified risk factors are strongly recommended for all women.

\section{Abbreviations}

AOR, adjusted odds ratio; COR, crudes odds ratio; CI, confidence interval; HPV, human Papilloma virus; STI, sexually transmitted infections; VIA, visual inspection of uterine cervix with acetic acid.

\section{Data Sharing Statement}

Data are available from the corresponding author upon a reasonable request.

\section{Acknowledgment}

We would like to thank Madda Walabu University for its financial support for this study. We also thank all the data collectors who participated in this study.

\section{Author Contributions}

All authors made a significant contribution to the work reported, whether that is in the conception, study design, execution, acquisition of data, analysis and interpretation, or in all these areas; took part in drafting, revising or critically reviewing the article; gave final approval of the version to be published; have agreed on the journal to which the article has been submitted; and agree to be accountable for all aspects of the work.

\section{Disclosure}

The authors report no conflicts of interest in this work.

\section{References}

1. ACF (Anti cancer Fund). Cervical Cancer: A Guide for Patients Information Based on ESMO Clinical Practice Guidelines. Vol. 2012; 2012:1.

2. World Health Organization. IARC Handbooks of Cancer Prevention. Volume 10: Cervix Cancer Screening. IARC Handbooks of Cancer Prevention. Vol. 10. Cervix cancer screening; 2005.

3. Ostor AG. Natural history of cervical intraepithelial neoplasia: a critical review. Int J Gynecol Pathol. 1993;12:186-192. doi:10.1097/00004347-199304000-00018

4. De Vuyst H, Mugo NR, Chung MH, et al. Prevalence and determinants of human papillomavirus infection and cervical lesions in HIV-positive women in Kenya. Br J Cancer. 2012;107(9):1624. doi:10.1038/bjc.2012.441

5. Bruni L, Barrionuevo-Rosas L, Albero G, et al. 2017. ICO/IARC information centre on HPV and cancer (HPV information centre). Human papillomavirus and related diseases in the world. Summary Report.

6. WHO(world health organization). Fact sheet on cervical cancer 2018. Available from: https:/www.who.int/cancer/prevention/diagno sis-screening/cervical-cancer/en. Accessed May 11, 2019.

7. Ferlay J, Shin HR, Bray F, Forman D, Mathers C, Parkin DM. GLOBOCAN, Cancer Incidence and Mortality Worldwide: IARC CancerBase No. 10 [Internet]. Lyon, France: International Agency for Research on Cancer; 2010. globocan. iarc. fr; 2012.

8. Chumworathayi B, Blumenthal PD, Limpaphayom KK, Kamsa-ard S, Wongsena M, Supaatakorn P. Effect of single-visit VIA and cryotherapy cervical cancer prevention program in Roi Et, Thailand: a preliminary report. J Obstet Gynaecol Res. 2010;36 (1):79-85. doi:10.1111/j.1447-0756.2009.01089.x

9. Horo A, Jaquet A, Ekouevi DK, et al. Cervical cancer screening by visual inspection in Côte d'ivoire, operational and clinical aspects according to HIV status. BMC Public Health. 2012;12(1):237. doi:10.1186/1471-2458-12-237

10. Nwankwo KC, Aniebue UU, Aguwa EN, Anarado AN, Agunwah E. Knowledge attitudes and practices of cervical cancer screening among urban and rural Nigerian women: a call for education and mass screening. Eur J Cancer Care (Engl). 2011;20(3):362-367. doi:10.1111/j.1365-2354.2009.01175.x

11. FMOH (Federal Ministry of Health). National Cancer Control of Ethiopia 2016-2020, Disease Prevention and Control Directorate. Addis Ababa, Ethiopia; 2015.

12. Mitiku I, Tefera F. Knowledge about cervical cancer and associated factors among 15-49 year old women in Dessie Town, Northeast Ethiopia. PLoS One. 2016;11(9):e0163136.

13. Bayu H, Berhe Y, Mulat A, Alemu A, Grce M. Cervical cancer screening service uptake and associated factors among age eligible women in Mekelle Zone, Northern Ethiopia, 2015: a community based study using health belief model. PLoS One. 2016;11(3): e0149908. doi:10.1371/journal.pone.0149908

14. $\mathrm{WHO}$ (world health organization). Fact sheet on cervical cancer. 2013. Available from: http://www.who.int/cancer/prevention/diagno sis-screening/cervical-cancer/en/. Accessed April 5, 2018. 
15. American College of Obstetricians and Gynecologists. Committee on adolescent health care, immunization expert work group. Committee Opin Number. 2015;126:e38-e43. human papillomavirus vaccination.

16. Campos NG, Castle PE, Wright TC, Kim JJ. Cervical cancer screening in low-resource settings: a cost-effectiveness framework for valuing tradeoffs between test performance and program coverage. Int J Cancer. 2015;137(9):2208-2219. doi:10.1002/ijc.29594

17. Bruni L, Diaz M, Barrionuevo-Rosas L, et al. Global estimates of human papillomavirus vaccination coverage by region and income level: a pooled analysis. Lancet Global Health. 2016;4(7):e453-e463. doi:10.1016/S2214-109X(16)30099-7

18. Denny L, Quinn M, Sankaranarayanan R. Chapter 8: screening for cervical cancer in developing countries. Vaccine. 2006;24:S71-S77. doi:10.1016/j.vaccine.2006.05.121

19. World Health Organization. WHO Guidelines for Screening and Treatment of Precancerous Lesions for Cervical Cancer Prevention: Supplemental Material: GRADE Evidence-To-Recommendation Tables and Evidence Profiles for Each Recommendation; 2013.

20. Gaffikin L, Blumenthal PD, McGrath J, Chirenje ZM. Visual inspection with acetic acid for cervical-cancer screening: test qualities in a primary care setting. Lancet. 1999;353(9156):869.

21. Sankaranarayanan R, Gaffikin L, Jacob M, Sellors J, Robles S. A critical assessment of screening methods for cervical neoplasia. Int J Gynecol Obstet. 2005;89:S2. doi:10.1016/j.ijgo.2005.01.009

22. Sankaranarayanan R, Wesley R, Thara S, et al. Test characteristics of visual inspection with $4 \%$ acetic acid (VIA) and Lugol's iodine (VILI) in cervical cancer screening in Kerala, India. Int J Cancer. 2003;106:404-408. doi:10.1002/ijc.11245

23. Sankaranarayanan R, Basu P, Wesley RS, et al. Accuracy of visual screening for cervical neoplasia: results from an IARC multicentre study in India and Africa. Int $J$ Cancer. 2004;110(6):907-913. doi:10.1002/ijc. 20190

24. Belinson JL, Pretorius RG, Zhang WH, et al. Cervical cancer screening by simple visual inspection after acetic acid. Obstet Gynecol. 2001;98:441-444.

25. Bezabih M, Tessema F, Sengi H, Deribew A. Risk factors associated with invasive cervical carcinoma among women attending Jimma University specialized hospital, Southwest Ethiopia: a case control study. Ethiop J Health Sci. 2015;25:345-352. doi:10.4314/ejhs.v25i4.8

26. Teame H, Addissie A, Ayele W, et al. Factors associated with cervical precancerous lesions among women screened for cervical cancer in Addis Ababa, Ethiopia: a case control study. PLoS One. 2018;13(1): e0191506. doi:10.1371/journal.pone.0191506

27. Getinet M, Gelaw B, Sisay A, Mahmoud EA, Assefa A. Prevalence and predictors of Pap smear cervical epithelial cell abnormality among HIV-positive and negative women attending gynecological examination in cervical cancer screening center at Debre Markos referral hospital, East Gojjam, Northwest Ethiopia. BMC Clin Pathol. 2015;15(1):16. doi:10.1186/s12907-015-0016-2
28. Kassa RT. Risk factors associated with precancerous cervical lesion among women screened at Marie Stops Ethiopia, Adama town, Ethiopia 2017: a case control study. BMC Res Notes. 2018;11 (1):145. doi:10.1186/s13104-018-3244-6

29. Hailemariam T, Yohannes B, Aschenaki H, et al. Prevalence of cervical cancer and associated risk factors among women attending cervical cancer screening and diagnosis center at Yirgalem General Hospital, Southern Ethiopia. J Cancer SciTher. 2017;9:730-735. doi:10.4172/1948-5956.1000500

30. Gessese Z, Tadesse Z, Alemayehu M, et al. Determinant factors of Visual Inspection with Acetic Acid (VIA) positive lesions among HIV positive women in Mekelle Hospital, Northern Ethiopia: a case control study. Ethiop Med J. 2015;53.

31. Castellsague X, Munoz N. Chapter 3: cofactors in human papillomavirus carcinogenesis--role of parity, oral contraceptives, and tobacco smoking. J Natl Cancer Inst Monogr. 2003;2003(31):20-28. doi:10.1093/oxfordjournals.jncimonographs.a003477

32. Jensen KE, Schmiedel S, Norrild B, et al. Parity as a cofactor for high-grade cervical disease among women with persistent human papillomavirus infection: a 13-year follow-up. $\mathrm{Br} J$ Cancer. 2013;108(1):234-239. doi:10.1038/bjc.2012.513

33. Makuza JD, Nsanzimana S, Muhimpundu MA, Pace LE, Ntaganira J, Riedel DJ. Prevalence and risk factors for cervical cancer and pre-cancerous lesions in Rwanda. Pan Afr Med J. 2015;22(1). doi:10.11604/pamj.2015.22.26.7116

34. Cohen O, Schejter E, Agizim R, et al. Postcoital bleeding is a predictor for cervical dysplasia. PLoS One. 2019;14(5):e0217396. doi:10.1371/journal.pone.0217396

35. Roura E, Castellsague X, Pawlita M, et al. Smoking as a major risk factor for cervical cancer and pre-cancer: results from the EPIC cohort. Int J Cancer. 2014;135(2):453-466. doi:10.1002/ijc.28666

36. Fang J-H, Yu X-M, Zhang S-H, Yang Y. Effect of smoking on high-grade cervical cancer in women on the basis of human papillomavirus infection studies. J Cancer Res Ther. 2018;14(8):184-189. doi:10.4103/0973-1482.179190

37. Gedefaw A, Astatkie A, Tessema GA, Atashili J. The prevalence of precancerous cervical cancer lesion among HIV-infected women in Southern Ethiopia: a cross-sectional study. PLoS One. 2013;8(12): e84519. doi:10.1371/journal.pone.0084519

38. Izudi J, Adrawa N, Amongin D. Precancerous cervix in human immunodeficiency virus infected women thirty years old and above in Northern Uganda. Hindawi Publishing Corporation. J Oncol. 2016;7. doi:10.1155/2016/5473681

39. Utoo BT, Utoo PM, Ngwan SD, Anzaku SA, Daniel MA. Cervical intraepithelial neoplasia: prevalence, risk factors, and utilization of screening services among an urban population in Nigeria. Trop J Obstet Gynaecol. 2016;33(3):279. doi:10.4103/0189-5117.199810

\section{Publish your work in this journal}

The International Journal of Women's Health is an international, peerreviewed open-access journal publishing original research, reports, editorials, reviews and commentaries on all aspects of women's healthcare including gynecology, obstetrics, and breast cancer. The manuscript management system is completely online and includes a very quick and fair peer-review system, which is all easy to use. Visit http://www.dovepress.com/testimonials.php to read real quotes from published authors. 